\section{Macrolides: Are They Safe Bet in Management of Community Acquired Pneumonia (CAP) in Elderly Patients Admitted to an Intensive Care Unit (ICU)}

\begin{abstract}
Anumakonda V
Dudley Group of Hospitals, NHS Foundation Trust, Birmingham, West Midlands, UK
\end{abstract}

Corresponding author: Anumakonda V

” vikramanumakonda@gmail.com

\section{Abstract}

ICNARC data from UK ICU has demonstrated $125 \%$ increase in patients requiring ICU admission for advance ventilator support following a severe CommunityAcquired Pneumonia (CAP). They constitute one of critically ill patient's cohorts in ICU. Cardiovascular (CVS) morbidity and mortality associated with CAP has been well-known for several decades. Macrolides form integral part of antibiotic bundle worldwide in management of severe CAP in the ICU setting. We attempt to suggest strategy to mitigate CVS morbidity and mitigate this risk.

Keywords: Multilobar chest radiograph; Respiratory rate; Arterial pH; Morbidity

Abbreviations: CAP: Community-Acquired Pneumonia; CURB65: Confusion, Urea $>7 \mathrm{mmol} / \mathrm{l}$, Respiratory rate $\geq 30 / \mathrm{min}$, Blood Pressure $<90 \mathrm{mmHg}$ Systolic and/or Diastolic Blood Pressure $\leq 60 \mathrm{mmHg}$, Age $\geq 65$ Years; ICU: Intensive Care Unit

Received: February 05, 2017; Accepted: March 16, 2017; Published: March 23, 2017

\begin{abstract}
M.B.B.S, FRCP, FFICM, Consultant Physician, Critical Care Medicine, Acute Medicine and General Internal Medicine, Dudley Group of Hospitals, NHS Foundation Trust, Birmingham, West Midlands, UK.
\end{abstract}

Tel: 01384456111

Citation: Anumakonda V. Macrolides: Are They Safe Bet in Management of Community Acquired Pneumonia (CAP) in Elderly Patients Admitted to an Intensive Care Unit (ICU). Insights Chest Dis. 2017, 2:1.

\section{Introduction}

Community-Acquired Pneumonia (CAP) is a common and potentially serious illness [1-5]. An acute severe infection of lung parenchyma ultimately leads to grey hepatisation which impairs gas exchange across alveolar membrane. CAP is associated with considerable morbidity and mortality, particularly in elderly patients and those with significant comorbidities.

Pneumonia Severity Index (PSI) and British thoracic society CURB65 criteria were less predictive at outcomes such as requirement for ICU admission and need for invasive ventilation. They are of limited use in the critical care environment $[6,7]$.

\section{Epidemiology of CAP}

Daniel et al., recently reported patients with CAP were younger (78 vs. 80 years), significant respiratory symptoms including fever, cough, dyspnoea and pleuritic chest pain as compared to those patients with those patients coded as pneumonia on discharge. They had fewer constitutional symptoms and significantly higher mortality (17\% vs. $14.3 \%, p=0.003)$ [8]. However, Sub-Saharan Africa has significantly higher mortality in relatively young patient due to Human Immunodeficiency Virus (HIV) prevalence in the region; and coinfection with tuberculosis and opportunistic infections is common [9]. Feldman and Anderson reported significant cardiac complications in severe pneumococcal pneumonia despite herd immunity following pneumococcal conjugated vaccine [10]. Interestingly, in developed and developing countries, diabetes mellitus prevalence was significantly increased with CAP hospital admissions and was associated with longer hospital stay and increased mortality [11]. In temperate and subtropical climates; Murdoch et al, demonstrated an association between seasonal variation and the occurrence of CAP [12].

At present, overall about $22-42 \%$ of CAP patients require hospital admission [13-15], of whom 5-10\% will be admitted to an ICU [16-18]. Hospital and ICU admission rates for CAP are increasing for all ages [13].

In a Finnish study, the incidence of CAP rose dramatically with age, with a six-fold increase in incidence between ages 30-44 years and $\geq 75$ years [16]. In Portugal, case fatality rates were $4.5 \%$ for patients aged $18-50$ years, $19.4 \%$ for those aged $\geq 50$ years and $24.8 \%$ for those aged $\geq 75$ years [19]. A UK study reported case-fatality rates of $5.6 \%$ in those aged $<65$ years and $47.2 \%$ for those aged $\geq 85$ years. This study also found a 12 -fold higher OR for death within 30 days of hospital admission for adults aged $\geq 85$ years than for those aged $<65$ years [20]. With the projected 
increase of those aged $\geq 65$ years to $20 \%$ of the adult population in developed regions of the world by 2025 [21], the burden of CAP will be felt even more acutely in the years to come.

\section{Pathogens}

The most commonly identified pathogens are Streptococcus pneumoniae, Haemophilus influenzae, atypical bacteria (i.e., Chlamydia pneumoniae, Mycoplasma pneumoniae and Legionella species) and viruses [22,23]. Prognosis is excellent for relatively young or healthy patients. But CAP especially when caused by S. pneumoniae, Legionella, Staphylococcus aureus, or influenza virus, are serious or even fatal in elderly patients.

\section{Cardiovascular Stress and Morbidity in Elderly CAP Patients}

The physiological changes and cardiopulmonary interactions in mechanical ventilated patients are significantly different with respect to normal breathing conditions. Lung-protective ventilation, using lower tidal volumes, combining lower airway pressures with the open lung concept, aims to minimise barotrauma and atelectatic lung injury by Mechanical Ventilation (MV). Effects of MV on Right Ventricular (RV) loading have declined by lung-protective ventilation but remain unpredictable. Left Ventricle (LV) has a knock-on effect as both ventricles pump in series. In addition, both lung and chest wall compliance significantly affect the amount of positive airway pressure transmitted to the intra-thoracic cavity during $M V$, with huge inter-patient and intra-patient variability. Declining lung compliance often demands increments in applied airway pressures, thus likely resulting in increase in RV afterload. Contrary to this, impaired chest wall compliance has the potential to increase intra-thoracic pressures at unchanged tidal volumes likely decreasing RV preload. Furthermore, impaired baseline cardiac function or fluid status can aggravate the haemodynamic effects of mechanical ventilation. This can all lead to a vicious circle of hypotension and hypoxia with a decrease in coronary perfusion pressure and subsequent myocardial ischaemia, resulting in a further reduction in cardiac output [24].

Incidence for overall cardiac complications, incident heart failure, acute coronary syndromes and cardiac arrhythmias were reported by Corrales-Medina et al. to be $17.7 \%, 14.1 \%, 5.3 \%$, and $4.7 \%$ respectively [25]. However, Diaz et al. reported heart failure in almost quarter of these patients, and arrhythmias (15\%) in cases of severe CAP admitted to ICU [26].

Corrales-Medina et al., reported hospitalisation for pneumonia was associated with increased short-term and long-term risk of CVD and development of acute coronary syndromes $[25,27,28]$.

Moreover, hypoxemia associated with CAP can raise pulmonary arterial pressure and right ventricular afterload while impairing myocardial oxygen delivery [18].

Tachycardia, common in acute infections in the elderly, not only increases myocardial oxygen demand but also shortens the diastolic period in which coronary perfusion occurs $[25,29,30]$. The net result of these effects is a shift in the metabolic supply/ demand ratio of the myocardium and further impairment of its function in patients with pre-existing cardiac disease. In addition, Mavrogeni and Manoussakis have demonstrated using cardiac magnetic resonance imaging that heart failure in CAP can result from myocardial inflammation (myocarditis) [30].

Surges of biomechanical stress, as a result of increased sympathetic activity and other hemodynamic changes (i.e., alterations of the circulatory volume and the systemic and coronary vascular tone), can prompt plaque rupture [17]. Acute infections can also promote plaque disruption by increasing intraplaque inflammatory activity [25]. In this setting, CorralesMedina et al. suggested thrombus formation over a disrupted coronary plaque-a key step in the development of ACS-would be favoured by infection-induced prothrombotic changes in the blood and endothelium [27].

Corrales-Medina et al. reported atrial fibrillation as a most common of the cardiac arrhythmias [25]. Degraff et al. and Morganroth et al. have reported abnormalities in the cardiac conduction system in the setting of acute pneumonia [31,32].

Renaud et al., Charles et al., and Espana et al. have independently described scoring systems to predict ICU admission [33-35]. Higher morbidity and mortality in each of these studies were associated with acidosis, hypotension, hypo and hyperventilation, uraemia, confusion, hypoxaemia and multilobar infiltrates. Sligl et al. [13] noted that higher 1-year mortality amongst patients with high PSI score (modified for age). It could be attributed to poor myocardial perfusion and predisposition to arrhythmias following transient ischemia.

\section{Antimicrobial Therapy}

Faverio et al. concluded in ICU patients a beta-lactamic plus either a fluoroquinolone or a macrolide should be considered. However, Salimi et al. have demonstrated that macrolides induced reactive oxygen species formation, mitochondrial membrane permeabilization and mitochondrial swelling and finally cytochrome c release in cardiomyocyte mitochondria. These findings suggested that the toxicity of heart mitochondria is a starting point for cardiotoxic effects of macrolides including QT prolongation, torsades de pointes and arrhythmia. Wong et al. reported use of clarithromycin was associated with an increased risk of myocardial infarction, arrhythmia, and cardiac mortality short term. Cheng et al. reported administration of macrolide antibiotics is associated with increased risk for sudden cardiac death or ventricular tachyarrhythmia and cardiovascular death but not increased all-cause mortality [36-38].

Chou et al. reported adjusted Odds Ratio (OR) for ventricular arrhythmia were 4.32 (95\% confidence intervals (CI), 2.95-6.33) for azithromycin, $3.30(95 \% \mathrm{Cl}, 2.07-5.25)$ for moxifloxacin, and 1.41 (95\% Cl, 0.91-2.18) for levofloxacin. For cardiovascular death, the adjusted ORs for azithromycin, moxifloxacin, and 
levofloxacin were $2.62(95 \% \mathrm{Cl}, 1.69-4.06), 2.31$ (95\% Cl, 1.39$3.84)$, and 1.77 (95\% Cl, 1.22-2.59), respectively [30,38-44].

Pereyre et al. reported macrolide resistance has been spreading for 15 years worldwide, with prevalence now ranging between 0 and $15 \%$ in Europe and the USA, approximately $30 \%$ in Israel and up to $90-100 \%$ in Asia [42]. Justo and Zeltser reported that simple history taking and baseline electrocardiogram could predict "torse de pointes" induced by antibiotics [43].

Doxycycline or Levofloxacin with relative safe profile to macrolides could be considered in the elderly patients and where macrolide resistance is prevalent $[32,42]$.

Judicious use of procalcitonin to assess CAP severity and to shorten duration of antibiotic therapy, is probably best way forwards in limiting multidrug resistant pathogens [42-48].
Regular monitoring of QT interval in this cohort of patient should be integrated into routine ward round check list care bundle. In those with border line corrected QT interval, daily monitoring should be mandatory and drug implicated should be watch out for.

\section{Conclusion}

Antimicrobial cardiac safety is of particular concern during the treatment of community-acquired pneumonia (CAP) in elderly patients, due to the presence of comorbid conditions and the use of multiple medications that may individually or synergistically affect cardiac repolarization. As a part of routine ICU ward round check list care bundle, QT interval monitoring should be done. ICU physicians should be vigilant to these cardiac complications of macrolides and minimize duration of exposure to these agents to best possible extent. 


\section{References}

1 File TM (2003) Community-acquired pneumonia. Lancet 362: 1991 2001.

2 Mandell LA, Wunderink RG, Anzueto A, Bartlett JG, Campbell GD et al. (2007) Infectious Diseases Society of America/American Thoracic Society consensus guidelines on the management of communityacquired pneumonia in adults. Clin Infect Dis 44: S27-S72.

3 Wunderink RG, Waterer GW (2014) Clinical practice. Communityacquired pneumonia. N Engl J Med 370: 543-551.

4 Musher DM, Thorner AR (2014) Community-acquired pneumonia. N Engl J Med 371: 1619-1628.

5 Prina E, Ranzani OT, Torres A (2015) Community-acquired pneumonia. Lancet 386: 1097-1108.

6 Metlay JP, Fine MJ (2003) Testing strategies in the initial management of patients with community-acquired pneumonia. Ann Intern Med 138: 109-118.

7 Lim WS, van der Eerden MM, Laing R, Boersma WG, Karalus N, et al. (2003) Defining community acquired pneumonia severity on presentation to hospital: an international derivation and validation study. Thorax 58: 377-382.

8 Daniel P, Bewick T, Welham S, Mckeever TM, Lim WS (2017) Adults miscoded and misdiagnosed as having pneumonia: results from the British Thoracic Society pneumonia audit. Thorax.

9 Aston SJ, Rylance J (2016) Community-Acquired Pneumonia in SubSaharan Africa. Semin Respir Crit Care Med 37: 855-867.

10 Feldman C, Anderson R (2016) Epidemiology, virulence factors and management of the pneumococcus. F1000Res 5: 2320.

11 Martins M, Boavida JM, Raposo JF, Froes F, Nunes B (2016) Diabetes hinders community-acquired pneumonia outcomes in hospitalized patients. BMJ Open Diabetes Res Care 4: e000181.

12 Murdoch KM, Mitra B, Lambert S, Erbas B (2014) What is the seasonal distribution of community acquired pneumonia over time? A systematic review. Australas Emerg Nurs J 17: 30-42.

13 Sligl WI, Eurich DT, Marrie TJ, Majumdar SR (2010) Age still matters: prognosticating short- and long-term mortality for critically ill patients with pneumonia. Crit Care Med 38: 2126-2132.

14 Woodhead MA, Macfarlane JT, McCracken JS, Rose DH, Finch RG (1987) Prospective study of the aetiology and outcome of pneumonia in the community. Lancet 1: 671-674.

15 Guest JF, Morris A (1997) Community-acquired pneumonia: the annual cost to the National Health Service in the UK. Eur Respir J 10: 1530-1534.

16 Jokinen C, Heiskanen L, Juvonen H, Kallinen S, Karkola K, et al. (1993) Incidence of community-acquired pneumonia in the population of four municipalities in eastern Finland. Am J Epidemiol 137: 977-988.

17 The British Thoracic Society Research Committee, The Public Health Laboratory Service (PHLS) (1992) The aetiology, management and outcome of severe community-acquired pneumonia on the intensive care unit. Respir Med 86: 7-13.

18 Almirall J, Mesalles E, Klamburg J, Parra O, Agudo A (1995) Prognostic factors of pneumonia requiring admission to the intensive care unit. Chest 107: 511-516.

19 Froes F (2003) Community-acquired pneumonia in adults in mainland Portugal-incidence and mortality in hospital inpatients between 1998 and 2000. Rev Port Pneumol 9: 187-194.
20 Trotter CL, Stuart JM, George R, Miller E (2008) Increasing hospital admissions for pneumonia, England. Emerg Infect Dis 14: 727-733.

21 Department of Economic and Social Affairs, Population Division (2007) World Population Prospects: The Revision. United Nations.

22 Menon RU, George AP, Menon UK (2013) Etiology and Anti-microbial Sensitivity of Organism causing Community Acquired Pneumonia: A Single Hospital Study. J Family Med Prim Care 2: 244-249.

23 Iroezindu MO, Chima El, Isiguzo GC, Mbata GC, Onyedum CC, et al. (2014) Sputum bacteriology and antibiotic sensitivity patterns of communityacquired pneumonia in hospitalized adult patients in Nigeria: a 5-year multicentre retrospective study. Scand J Infect Dis 46: 875-887.

24 Cherpanath TG, Lagrand WK, Schultz MJ, Groeneveld AB (2013) Cardiopulmonary interactions during mechanical ventilation in critically ill patients. Neth Heart J 21: 166-172.

25 Corrales-Medina VF, Suh KN, Rose G, Chirinos JA, Doucette S, et al. (2011) Cardiac Complications in Patients with Community-Acquired Pneumonia: A Systematic Review and Meta-Analysis of Observational Studies. PLoS Med 8: e1001048.

26 Díaz A, Alvarez M, Callejas C, Rosso R, Schnettler K, et al. (2005) [Clinical picture and prognostic factors for severe communityacquired pneumonia in adults admitted to the intensive care unit]. Arch Bronconeumol 41: 20-26.

27 Corrales-Medina VF, Alvarez KN, Weissfeld LA, Angus DC, Chirinos JA, et al. (2015) Association between hospitalization for pneumonia and subsequent risk of cardiovascular disease. JAMA 313: 264-274.

28 Corrales-Medina VF, Madjid M, Musher DM (2010) Role of acute infection in triggering acute coronary syndromes. Lancet Infect Dis 10: 83-92.

29 Torres A, Serra-Batlles J, Ferrer A, Jiménez P, Celis R, et al. (1991) Severe community-acquired pneumonia. Epidemiology and prognostic factors. Am Rev Respir Dis 144: 312-318.

30 Mavrogeni S, Manoussakis MN (2010) Myocarditis as a complication of influenza A (H1N1): evaluation using cardiovascular magnetic resonance imaging. Hellenic J Cardiol 51: 379-380.

31 Degraff AC, Travell JG, Yager JA (1931) An electrocardiographic study of the heart in lobar pneumonia. J Clin Invest 10: 633-651.

32 Morganroth J, Dimarco JP, Anzueto A, Niederman MS, Choudhri S (2005) A randomized trial comparing the cardiac rhythm safety of moxifloxacin vs levofloxacin in elderly patients hospitalized with community-acquired pneumonia. Chest 128: 3398-3406.

33 Renaud B, Labarère J, Coma E, Santin A, Hayon J, et al. (2009) Risk stratification of early admission to the intensive care unit of patients with no major criteria of severe community-acquired pneumonia: development of an international prediction rule. Crit Care 13: R54.

34 Charles PG, Wolfe R, Whitby M, Fine MJ, Fuller AJ, et al. (2008) SMART-COP: a tool for predicting the need for intensive respiratory or vasopressor support in community-acquired pneumonia. Clin Infect Dis 47: 375-384.

35 España PP, Capelastegui A, Gorordo I, Esteban C, Oribe M, et al. (2006) Development and validation of a clinical prediction rule for severe community-acquired pneumonia. Am J Respir Crit Care Med 174: 1249-1256.

36 Sarnoff SJ, Braunwald E, Welch GH Jr, Case RB, Stainsby WN, et al. (1958) Hemodynamic determinants of oxygen consumption of the heart with special reference to the tension-time index. Am J Physiol 192: $148-156$ 
37 Merkus D, Kajiya F, Vink H, Vergroesen I, Dankelman J, et al. (1999) Prolonged diastolic time fraction protects myocardial perfusion when coronary blood flow is reduced. Circulation 100: 75-81.

38 Faverio P, Aliberti S, Bellelli G, Suigo G, Lonni S, et al. (2014) The management of community-acquired pneumonia in the elderly. Eur J Intern Med 25: 312-319.

39 Salimi A, Eybagi S, Seydi E, Naserzadeh P, Kazerouni NP, et al. (2016) Toxicity of macrolide antibiotics on isolated heart mitochondria: a justification for their cardiotoxic adverse effect. Xenobiotica 46: 82-93.

40 Wong AY, Root A, Douglas IJ, Chui CS, Chan EW, et al. (2016) Cardiovascular outcomes associated with use of clarithromycin: population based study. BMJ 352: h6926.

41 Cheng YJ, Nie XY, Chen XM, Lin XX, Tang K, et al. (2015) The Role of Macrolide Antibiotics in Increasing Cardiovascular Risk. J Am Coll Cardiol 66: 2173-2184.

42 Pereyre S, Goret J, Bébéar C (2016) Mycoplasma pneumoniae: Current Knowledge on Macrolide Resistance and Treatment. Front Microbiol 7: 974.
43 Justo $D$, Zeltser $D$ (2006) Torsades de pointes induced by antibiotics. Eur J Intern Med 17: 254-259.

44 Chou HW, Wang JL, Chang CH, Lai CL, Lai MS, et al. (2015) Risks of cardiac arrhythmia and mortality among patients using new-generation macrolides, fluoroquinolones, and $\beta$-lactam/ $\beta$-lactamase inhibitors: a Taiwanese nationwide study. Clin Infect Dis 60: 566-577.

45 Ohtani H, Taninaka C, Hanada E, Kotaki H, Sato H, et al. (2000) Comparative Pharmacodynamic Analysis of Q-T Interval Prolongation Induced by the Macrolides Clarithromycin, Roxithromycin, and Azithromycin in Rats. Antimicrob Agents Chemother 44: 2630-2637.

46 Montassier E, Goffinet N, Potel G, Batard E (2013) How to reduce antibiotic consumption for community-acquired pneumonia? Med Mal Infect 43: 52-59.

47 Lacoma A, Rodríguez N, Prat C, Ruiz-Manzano J, Andreo F, et al. (2012) Usefulness of consecutive biomarkers measurement in the management of community-acquired pneumonia. Eur J Clin Microbiol Infect 31: 825-833.

48 Pinzone MR, Cacopardo B, Abbo L, Nunnari G (2014) Duration of antimicrobial therapy in community acquired pneumonia: less is more. Sci World J 2014: 759138. 